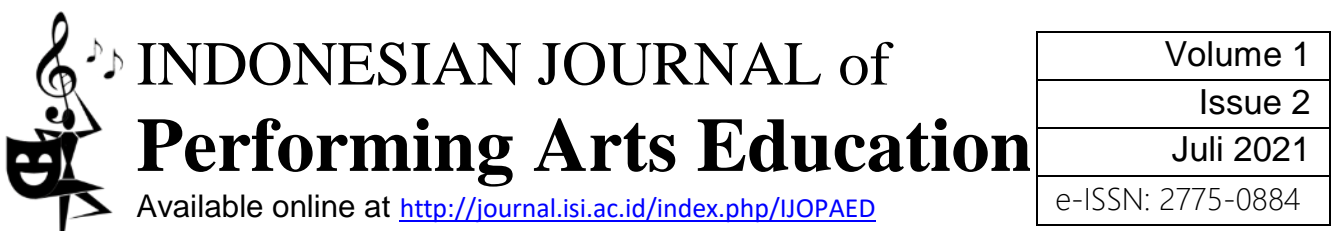
DOI suffix at https://doi.org/10.24821/ijopaed

\title{
PEMANFAATAN LOGIC PRO X DAN E-GAMELAN SEBAGAI ALTERNATIF MEDIA PEMBELAJARAN PRAKTIK KARAWITAN SECARA DARING
}

\author{
Mas Drajad Jiwandono ${ }^{1}$, Dilla Octavianingrum², Gandung Djatmiko ${ }^{3}$ \\ ${ }^{1}$ Institut Seni Indonesia Yogyakarta; masjiwan21@gmail.com \\ ${ }^{2}$ Institut Seni Indonesia Yogyakarta; dillaoctavia@isi.ac.id \\ ${ }^{3}$ Institut Seni Indonesia Yogyakarta; gandung.djatmiko@isi.ac.id
}

\begin{tabular}{|c|c|}
\hline $\begin{array}{l}\text { Doc Archive } \\
\text { Submited: } 30-06-2021 \\
\text { Accepted: } 21-07-2021 \\
\text { Published: } 31-07-2021 \\
\text { Keywords } \\
\text { e-gamelan; media } \\
\text { pembelajaran; } \\
\text { pembelajaran musik; } \\
\text { pembelajaran karawitan }\end{array}$ & $\begin{array}{l}\text { Abstrak } \\
\text { Masa darurat COVID-19 menuntut proses pembelajaran dilakukan } \\
\text { secara daring. Hal ini menghambat proses pembelajaran praktik karawitan } \\
\text { di SMP Negeri } 2 \text { Kretek, Bantul DIY. Oleh karena itu inovasi media } \\
\text { pembelajaran cukup dibutuhkan seperti pemanfaatan Digital Audio } \\
\text { Workstation (DAW) Logic Pro X dan aplikasi E-Gamelan. Tujuan } \\
\text { penelitian ini adalah untuk mendeskripsikan penggunaan DAW Logic Pro } \\
\text { dan E-Gamelan sebagai alternatif media pembelajaran praktik karawitan } \\
\text { secara daring. Pengumpulan data ditempuh mulai dari observasi, } \\
\text { wawancara, dan analisis dokumen yang berkaitan dengan permasalahan } \\
\text { tersebut. Sumber data dalam penelitian ini adalah guru dan peserta didik di } \\
\text { sekolah terkait. Teknik validasi pada penelitian ini menggunakan validasi } \\
\text { triangulasi teknik. Hasil penelitian menunjukkan bahwa penggunaan } \\
\text { media Logic Pro X dan E-Gamelan dalam proses pembelajaran praktik } \\
\text { karawitan SMP cukup efektif membantu guru dalam mencapai tujuan } \\
\text { pembelajaran. Lebih lanjut, sebagian besar para siswa memberikan respon } \\
\text { positif terhadap proses pembelajaran yang dilaksanakan. }\end{array}$ \\
\hline $\begin{array}{l}\text { Keywords } \\
\text { e-gamelan; learning } \\
\text { media; music learning; } \\
\text { karawitan learning }\end{array}$ & $\begin{array}{l}\text { Abstract } \\
\text { The COVID-19 emergency period demands that the learning process } \\
\text { be carried out online. This hinders the learning process of karawitan } \\
\text { practice at SMP Negeri } 2 \text { Kretek, Bantul DIY. Therefore, learning media } \\
\text { innovations are needed, such as Digital Audio Workstation (DAW), Logic } \\
\text { Pro X and the E-Gamelan application. This study aims to describe the use } \\
\text { of DAW Logic Pro and E-Gamelan as alternative media for learning } \\
\text { karawitan practice online. Data collection was taken starting from } \\
\text { observation, interviews, and analysis of documents related to these } \\
\text { problems. Sources of data in this study were teachers and students in } \\
\text { affiliated schools. The validation technique uses a triangulation validation } \\
\text { technique. The study results indicate that using Logic Pro X and E- } \\
\text { Gamelan media in the learning process of junior high school karawitan } \\
\text { practice is quite effective in helping teachers achieve learning goals. } \\
\text { Furthermore, most of the students gave a positive response to the learning } \\
\text { process carried out. }\end{array}$ \\
\hline
\end{tabular}




\section{Pendahuluan}

Seni Karawitan sebagai salah satu cabang seni yang hidup, bertahan, dan berkembang di Indonesia khususnya pulau Jawa mempunyai fungsi yang cukup penting dalam kehidupan masyarakat. Baik dipandang dari sisi tekstual maupun kontekstual, seni Karawitan selalu berhubungan erat dengan masyarakat. Bagi masyarakat di Pulau Jawa, Seni Karawitan menjadi sebuah pertunjukan yang tidak asing dikarenakan dapat terlihat pada kegiatan-kegiatan seperti lomba karawitan, cokekan, pertunjukan wayang, pesta pernikahan dan lain sebagainya. Setiap masyarakat mempunyai peristiwa yang ditandai dengan musik "karawitan" yang dapat membangkitkan kebersamaan warganya dan mengingatkan kesatuan mereka (Sumarsam, 2003, p. 2).

Oleh karena itu, apabila Seni Karawitan dipelajari dengan baik dapat meningkatkan kebersamaan dan kesatuan dalam bermasyarakat. Karawitan merupakan kesenian yang menjadi sebuah warisan budaya bagi bangsa Indonesia. Karawitan mengandung nilai-nilai dan pengetahuan tentang kebudayaan yang perlu dilestarikan dari generasi ke generasi. Salah satu usaha pelestarian karawitan dilakukan dengan memasukkan materi karawitan ke dalam pembelajaran seni musik di sekolah.

Proses belajar mengajar di sekolah saat ini terkendala karena adanya pandemi COVID-19, tidak hanya sekolah bahkan sampai di tataran pendidikan tinggi seni (Pratama \& Dewi, 2020; Pratama \& Surahman, 2020). Masa darurat COVID-19 menuntut proses pembelajaran untuk dilakukan secara daring sesuai dengan Permendikbud No. 33/2019 (2019). Hal tersebut menghambat proses pembelajaran praktik karawitan kelas VIII di SMP Negeri 2 Kretek, Bantul DIY. Oleh karena itu, inovasi yang berkaitan dengan proses pembelajaran daring perlu dilakukan. Salah satunya adalah pemanfaatan media pembelajaran untuk mendukung proses pembelajaran praktik karawitan. Peran media pada pembelajaran daring cukup dibutuhkan, begitu juga dalam proses pembelajaran praktik. Tidak menutup kemungkinan pemanfaatan media pembelajaran dilakukan mengingat perkembangan teknologi yang terus meningkat.

Perkembangan teknologi yang terjadi saat ini memberikan pengaruh yang besar terhadap media pembelajaran. Pembelajaran yang dulu lebih banyak menggunakan cara-cara dan metode konvensional, sekarang bisa dilakukan dengan lebih praktis menggunakan teknologi digital. Salah satunya adalah pembelajaran praktik karawitan yang dilakukan secara daring menggunakan media Digital Audio Workstation (DAW) dan aplikasi E-Gamelan.

Media erat kaitannya dengan proses pembelajaran. Dalam proses pembelajaran, media seringkali diartikan sebagai alat-alat grafis, photografis, atau alat elektronik yang berfungsi untuk menangkap, memproses, dan menyusun kembali informasi visual atau verbal (Wati, 2016, p. 2). Garlach dan Erly menyatakan bahwa media apabila dipahami secara garis besar adalah manusia, materi, atau kejadian yang membangun kondisi yang membuat siswa mampu memperoleh pengetahuan, keterampilan, atau sikap (Arsyad, 2019).

Metode pembelajaran menurut Reigeluth (Dewi, 2018) adalah mempelajari sebuah proses yang mudah diketahui, diaplikasikan dan diteorikan dalam membantu pencapaian hasil belajar. Berbagai metode dilakukan untuk menjamin guru dan siswa agar mampu mengembangkan proses belajar mengajar guna menunjang pencapaian hasil belajar dalam kualitas Pendidikan. Penerapan metode pembelajaran yang tepat dalam proses belajarmengajar dapat mempengaruhi respon peserta didik untuk menyerap atau menerima materi pelajaran. Pada pembelajaran praktik karawitan secara daring biasa digunakan metode ceramah dan demonstrasi. Selain media dan metode tentunya gaya belajar para pebelajar juga komponen penting dalam pembelajaran seni (Pratama, 2020).

Media Digital Audio Workstation (DAW) dapat digunakan guru untuk mengemas atau membuat materi praktik karawitan ke dalam bentuk ekstensi berkas WAV dan MP3. Hal ini dilakukan dengan maksud supaya siswa lebih mudah memahami dan menghafal materi praktik karawitan jawa dengan bantuan audio. Media EGamelan dapat digunakan siswa sebagai simulasi permainan gamelan. Hal tersebut bertujuan untuk melatih kepekaan dan keterampilan siswa dalam bermain gamelan serta dapat tercapainya tujuan pembelajaran praktik secara daring.

DAW adalah sebuah software yang didesain untuk mengakomodasi penggunanya untuk merekam, mixing, mastering, mengubah suara yang telah direkam (editing) dan membuat musik (Wardhana, n.d.). DAW biasanya digunakan untuk produksi musik dan sudah banyak mengalami perkembangan. Saat ini bisa 
dikatakan bahwa produk-produk DAW tidak hanya mampu menggantikan semua kebutuhan yang ada dalam studio rekaman, tetapi juga mampu membuat proses produksi musik menjadi semakin mudah.

Cara menggunakan teknologi DAW bukan hal yang susah, karena menggunakan teknologi ini adalah sesuatu yang dapat dipelajari oleh semua orang. Terdapat beberapa macam DAW di antaranya FL Studio, Studio One, Logic Pro, Cubase dan lain sebagainya dengan cara kerja yang hampir sama. Oleh karena itu, sebelum mempelajari teknologi ini alangkah baiknya untuk menentukan salah satu DAW agar lebih bisa fokus dalam mempelajarinya. DAW yang digunakan dalam implementasi pembelajaran karawitan di SMP Negeri 2 Kretek adalah Logic Pro X. Logic Pro merupakan salah satu aplikasi untuk sistem MacOs (Apple Inc., 2021).

Sebagaimana software pada umumnya, DAW juga membutuhkan sebuah laptop atau komputer yang layak pakai agar dapat beroperasi dengan baik. Layak pakai yang dimaksud adalah spesifikasi laptop atau komputer yang sudah cukup baik seperti CPU atau prosesor minimal Quadcore dan RAM minimal 4 GB. Hal ini menjadi kekurangan teknologi ini karena jika spesifikasi laptop atau komputer tidak diperhatikan maka akan menjadi masalah dalam penggunaannya. Selain itu, jika spesifikasi cukup baik maka pengoperasian DAW akan lebih nyaman saat digunakan.

Pembuatan sample atau contoh musik menggunakan teknologi DAW bisa dibilang cukup efisien. Penggunaan yang mudah dan kelengkapan instrumen untuk komposisi musik yang hampir kompleks. Oleh karena itu, teknologi ini tidak menutup kemungkinan untuk dijadikan media pembelajaran khususnya pada bidang seni musik.

E-Gamelan merupakan aplikasi yang dibuat sebagai sarana edukasi dan pengetahuan mengenai gamelan, khususnya gamelan Jawa. Aplikasi ini dibuat oleh Sanggar Seni Grahatama yang dapat di unduh melalui ponsel cerdas Android di Google Play secara gratis (Sanggar Seni Grahatama, 2021). Aplikasi E-Gamelan menggunakan konsep audio-visual sehingga mudah dipahami oleh penggunanya. Penggunaan aplikasi ini cukup mudah yaitu dengan cara menekan layar yang bergambar instrumen gamelan untuk mengetahui bunyinya.

Penelitian ini dilakukan dengan tujuan untuk mendeskripsikan proses pembelajaran praktik gamelan secara daring dengan menggunakan bantuan DAW dan E-Gamelan. Penelitian ini didasari atas penerapan metode dan media pembelajaran audio untuk mengajarkan seni karawitan.

\section{Metode}

Pada penelitian ini digunakan jenis penelitian kualitatif. Penelitian dilakukan dengan cara mengetahui permasalahan pada proses pembelajaran secara daring. Pengumpulan data dilalui dengan observasi, wawancara hingga analisis dokumen yang berkaitan dengan permasalahan tersebut. Prosedur penelitian yang digunakan mengacu pada teori prosedur penelitian kualitatif Danim dan Darwis (2003, p. 80). Adapun prosedur penelitiannya adalah merumuskan masalah sebagai fokus penelitian, mengumpulkan data di lapangan, menganalisis data, merumuskan hasil studi, dan menyusun rekomendasi.

Desain penelitian yang dilakukan dalam studi ini adalah pendekatan kualitatif, yang menekankan analisisnya pada data yang telah diperoleh pada saat penelitian dilaksanakan.

Teknik validasi pada penelitian ini menggunakan validasi triangulasi teknik. Triangulasi teknik untuk menguji kredibilitas data yang dilakukan dengan cara mengecek data kepada sumber yang sama dengan teknik yang berbeda (Sugiyono, 2014, p. 127). Misalnya data diperoleh dengan wawancara lalu dicek dengan observasi, dokumentasi atau kuisioner. Kemudian proses analisis data dilakukan melalui dua fase selama (on going) dan setelah selesainya (after) pengumpulan data.

\section{Hasil dan Pembahasan}

Gamelan terdapat dalam materi pelajaran Seni Karawitan Jawa. Mata pelajaran ini sesuai dengan silabus pembelajaran SMP pada KD 4.4, yaitu memainkan ansambel musik tradisional. Pembelajaran karawitan dilakukan satu minggu sekali dengan waktu pelajaran $2 \times 40$ menit. Materi pyang diberikan berupa teori dan praktik. Materi teori karawitan Jawa kelas VIII meliputi pengetahuan karawitan jawa, nama-nama bentuk gamelan, jenis kategori alat musik pada gamelan, membaca notasi dan tangga nada gamelan. Sedangkan materi praktik karawitan yang diberikan adalah Gendhing Gangsaran.

Proses pembelajaran karawitan dilaksanakan secara daring melalui pemanfaatan Google Meet, Google Form dan WhatsApp. Google Meet digunakan untuk proses pertemuan tatap muka secara virtual. Google Form 
digunakan untuk pemberian tugas dan presensi siswa. Kemudian WhatsApp digunakan untuk menginformasikan segala hal tentang proses pembelajaran dan untuk mengontrol siswa dalam belajar. Metode pembelajaran yang digunakan pada proses adalah tanya jawab, ceramah, dan demonstrasi secara daring. Metode ceramah dilakukan pada saat proses belajar mengajar berlangsung secara tatap maya melalui video conference. Metode ceramah ini bertujuan untuk memberi penjelasan kepada siswa tentang materi teori. Metode tanya jawab dilakukan pada saat proses pembelajaran berlangsung secara daring melalui video conference. Kemudian demonstrasi digunakan untuk memberi pemahaman materi praktik melalui video-video tutorial. Metode ini bertujuan untuk membantu kemudahan siswa dalam proses belajar praktik karawitan.

Pada pembelajaran daring seni karawitan di SMP Negeri 2 Kretek, digunakan juga media pembelajaran DAW dan E-Gamelan. DAW digunakan guru untuk membuat contoh musik atau sample gendhing sebagai sumber belajar dan praktik siswa. Sedangkan E-Gamelan digunakan siswa untuk praktik bermain gamelan. Sekilas tampilan dari Logic Pro ada di Gambar 1 dan EGamelan ada pada Gambar 2.

Pembuatan sample musik Gendhing Gangsaran pada pembelajaran karawitan Jawa di SMP Negeri 2 Kretek menggunakan software DAW Logic Pro X. Proses membuat aransemen gamelan Jawa pada Logic Pro X menggunakan teknik sampling WAV yaitu, merekam suara dari setiap instrumen gamelan untuk dijadikan data midi dengan format berkas $W A V$. Format WAV sama halnya dengan format MP3, jadi file ini dapat disimpan dan digunakan untuk kebutuhan selanjutnya. Namun pada proses pembuatan sample musik Gendhing Gangsaran ini tidak perlu merekam setiap instrumen gamelan, karena sample midi WAV gamelan juga sudah ada. Sehingga proses pembuatan atau aransemen musik gendhing ini tidak menyita waktu yang lama. Waktu yang digunakan dalam proses pembuatan kurang lebih 30 menit.

Adapun langkah langkah proses pembuatan sample musik Gendhing Gangsaran menggunakan Logic Pro X sebagai berikut: (1) Menyiapkan notasi Gendhing Gangsaran; (2) Menyiapkan instrumen musik gamelan yang dibutuhkan. Pada pembuatan sample musik Gendhing Gangsaran ini membutuhkan instrumen gamelan kendang, bonang barung, bonang penerus, demung, saron, kenong, kempul dan gong; (3) Susun aransemen Gendhing
Gangsaran sesuai dengan notasi yang sudah dipersiapkan. Cara menyusunnya yaitu dengan record midi dari setiap instrumen menggunakan midi controller, atau dapat juga dengan cara menggambar pada setiap instrumen melalui piano roll. Rekam dan susun aransemen satu per satu sampai menjadi aransemen gendhing gangsaran yang utuh atau lengkap sesuai dengan notasi yang sudah disiapkan; (4) Setelah semuanya tersusun menjadi sebuah musik gendhing gangsaran, kemudian seimbangkan atau ratakan keras dan lemahnya suara dari setiap instrumen agar menjadi satu kesatuan musik yang balance; (5) Bouncing atau ekspor aransemen musik Gendhing Gangsaran ke dalam format MP3. Aransemen musik Gendhing Gangsaran di bouncing atau di ekspor menjadi dua file. File pertama adalah bouncing seluruh susunan aransemen Gendhing Gangsaran atau disebut bouncing aransemen lengkap. File kedua adalah bouncing susunan aransemen dengan mute atau menghilangkan salah satu suara intrumen gamelan. Jadi pada berkas kedua ini berisi 8 file musik sesuai dengan jumlah instrumen yang digunakan pada aransemen. File kedua ini yang akan digunakan siswa untuk belajar materi praktik karawitan menggunakan aplikasi EGamelan.

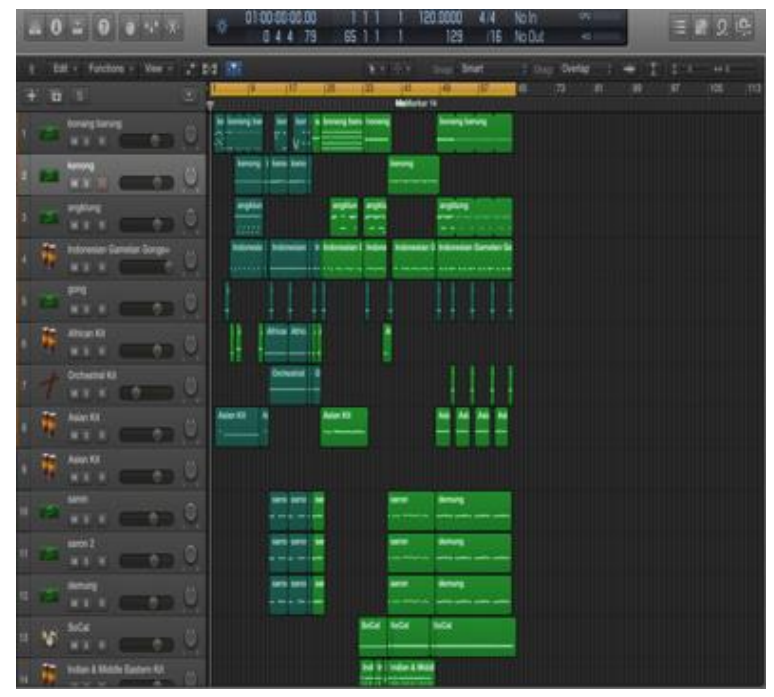

Gambar 1. Contoh Tampilan Logic Pro X

Pada E-Gamelan disediakan 11 intrumen gamelan seperti demung, saron, peking, kendhang, bonang barung, bonang penerus, slenthem, gender, gambang, gong-kempul dan kenong serta terdapat studio digital yang dapat dipakai menyusun aransemen instrumen secara sederhana. Dengan audio dan visual yang menyerupai bentuk nyata gamelan, aplikasi ini cukup membantu pemahaman siswa, menambah 
keterampilan dan pengetahuan khususnya gamelan jawa. Oleh karena itu, pemanfaatan aplikasi ini sebagai media pembelajaran jarak jauh cukup memungkinkan untuk menambah wawasan siswa pada materi terkait, yaitu gamelan Jawa.

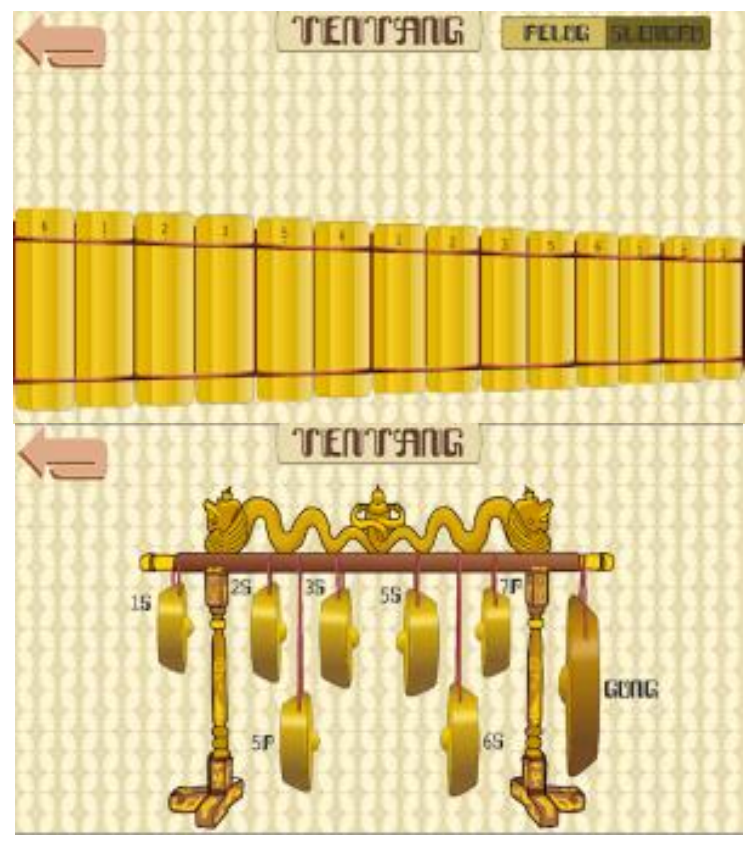

Gambar 2. Contoh Tampilan E-Gamelan

Proses pembelajaran Seni Karawitan yang dilakukan secara daring dengan menggunakan EGamelan membuat siswa lebih senang mengikuti pelajaran. Media pembelajaran ini juga cukup membantu siswa dalam proses belajar mulai dari memahami hingga mempraktikkan materi Seni Karawitan Jawa. Hal ini dibuktikan dengan respon siswa mengenai proses pembelajaran yang diberikan melalui Google Form. Pada pertanyaan pertama, yaitu tingkat kesulitan dalam mengikuti proses pembelajaran karawitan menggunakan aplikasi E-Gamelan, mendapatkan respon dari 27 siswa. Dari itu, ada 20 siswa memberikan jawaban bahwa tidak ada kesulitan dalam mengikut proses pembelajaran Seni Karawitan secara daring menggunakan E-Gamelan. Kemudian 7 siswa di antaranya memberikan jawaban berbeda, ada siswa yang merasa sedikit kesulitan dan ada siswa yang merasa sulit.

Pertanyaan kedua, yaitu tentang penggunaan media pembelajaran E-Gamelan apakah lebih menarik bagi siswa. Jawaban respon ini diantaranya ada 24 siswa yang menyatakan bahwa proses pembelajaran Seni Karawitan daring berbantukan E-Gamelan dianggap lebih menarik. Kemudian 3 siswa memberikan respon kurang menarik.
Pertanyaan ketiga yaitu manfaat pembelajaran karawitan secara daring menggunakan E-Gamelan, salah satunya adalah membuat siswa lebih semangat untuk belajar karawitan. Pertanyaan ini mendapatkan respon dari 15 siswa yang menyatakan bahwa proses pembelajaran daring Seni Karawitan berbantukan E-Gamelan membuat lebih semangat untuk belajar, karena proses pembelajaran praktik dapat dilaksanakan dalam cara alternatif. Kemudian 12 siswa memberikan respon yang berbeda-beda. Masih ada siswa yang lebih semangat apabila dapat melakukan praktik secara langsung, dan masih ada yang tidak terlalu semangat karena ponsel cerdas yang digunakan kurang mendukung.

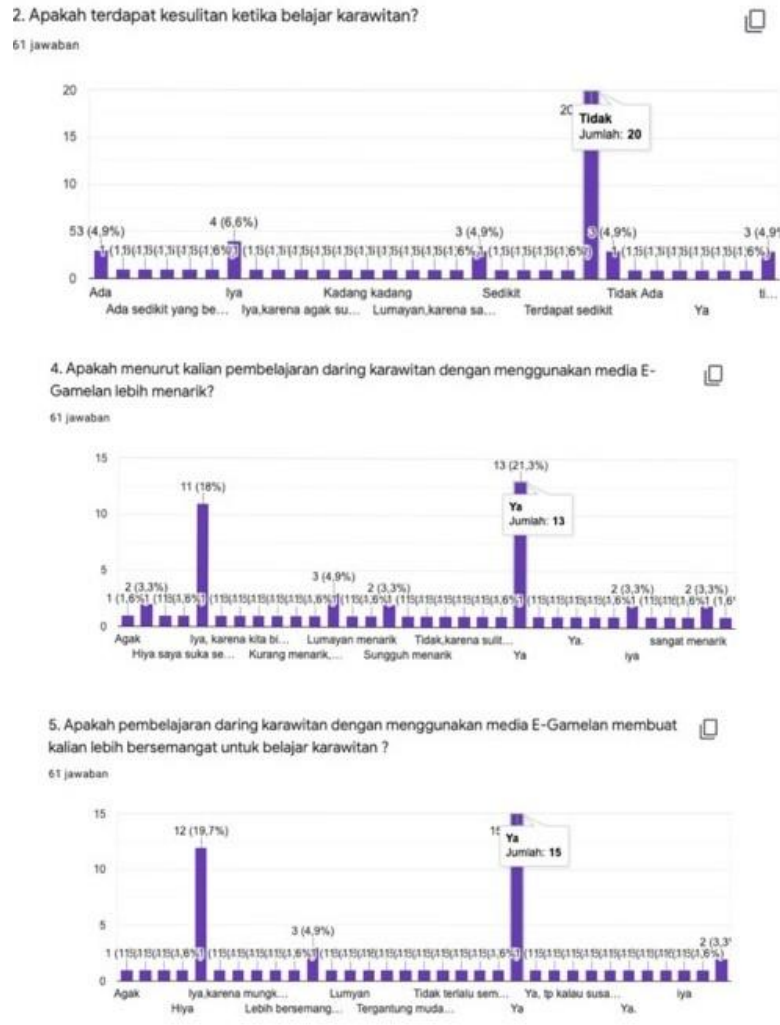

Gambar 3. Cuplikan Diagram Respon Siswa

Berdasarkan hasil yang diperoleh, dapat terlihat bahwa pembelajaran daring Seni Budaya materi Karawitan Jawa menjadi lebih lancar dan tujuan pembelajaran dapat tercapai, hal ini sangat dimungkinkan karena bantuan media DAW dan E-Gamelan. Pembelajaran daring karawitan Jawa yang sebelumnya hanya materi teori, lalu menjadi pembelajaran praktik juga. Praktik karawitan menggunakan E-Gamelan cukup memudahkan siswa untuk belajar praktik karawitan dimanapun dan kapanpun. Siswa merasa senang dan lebih mudah memahami materi pelajaran sehingga nilai siswa pada mata 
pelajaran Seni Budaya dapat meningkat. Pada hasil evaluasi pembelajaran, didapatkan nilai siswa dengan rata-rata 90.

\section{Kesimpulan}

Berdasarkan hasil penelitian dapat disimpulkan bahwa pembelajaran online praktik karawitan kelas VIII di SMP Negeri 2 Kretek dapat terlaksana dengan bantuan media EGamelan dan DAW Logic Pro X. Permainan EGamelan dan pembuatan sample musik karawitan dari Logic Pro $\mathrm{X}$ mempermudah guru dalam melaksanakan proses pembelajaran praktik karawitan, sehingga pembelajaran praktik karawitan dapat terlaksana.
Proses pembelajaran praktik karawitan secara daring tidak sepenuhnya terlaksana dengan baik, ada kekurangan dalam proses pembelajaran seperti beberapa siswa belum mempunyai ponsel cerdas, ruang penyimpanan perangkat siswa yang tidak cukup, dan keterbatasan paket data internet.

Penggunaan media DAW dan E-Gamelan dapat dijadikan salah satu solusi bagi guru untuk melaksanakan proses pembelajaran praktik karawitan secara daring. Penelitian selanjutnya dapat diproyeksikan guna mengkaji serta mengembangkan media pembelajaran lain yang lebih menarik dan efektif, mengingat bahwa seni budaya harus selalu diimbangi dengan kemajuan teknologi.

\section{Referensi}

Apple Inc. (2021). Logic Pro X. Retrieved from https://www.apple.com/logic-pro/

Arsyad, A. (2019). Media Pembelajaran (Revisi). Jakarta: Rajagrafindo Persada.

Danim, S., \& Darwis. (2003). Metode Penelitian Kebidanan: Prosedur, Kebijakan, dan Etik. Jakarta: EGC.

Dewi, E. R. (2018). Metode Pembelajaran Modern dan Konvensional pada Sekolah Menengah Atas. PEMBELAJAR: Jurnal Ilmu Pendidikan, Keguruan, Dan Pembelajaran, 2(1), 44-52. Retrieved from https://doi.org/10.26858/pembelajar.v2i1.5442

Kementerian Pendidikan dan Kebudayaan. Peraturan Menteri Pendidikan dan Kebudayaan tentang Penyelenggaraan Program Satuan Pendidikan Aman Bencana. , Pub. L. No. 33, 1 (2019).

Pratama, U. N. (2020). Analisis Gaya Belajar Mahasiswa Pendidikan Seni Pertunjukan Berdasarkan Modalitas Preferensi Sensori. JINOTEP Jurnal Inovasi Teknologi Pembelajaran, 7(2), 107-115. https://doi.org/10.17977/um031v7i22020p107

Pratama, U. N., \& Dewi, G. D. K. (2020). Implementasi Pembelajaran Online Berbasis Edmodo dalam Situasi Pandemik COVID-19 untuk Materi Kependidikan pada Prodi Pendidikan Seni Pertunjukan. PRASI: Jurnal Bahasa, Seni, Dan Pengajarannya, 15(02), 98-109. https://doi.org/10.23887/prasi.v15i01.

Pratama, U. N., \& Surahman, E. (2020). Investigating Student Responses of Online Learning during the Covid-19 Pandemic in Performing Art Education. Proceedings - 2020 6th International Conference on Education and Technology, ICET 2020, 64-69. https://doi.org/10.1109/ICET51153.2020.9276575

Sanggar Seni Grahatama. (2021). E-Gamelan - Virtual Javanese Gamelan. Retrieved from https://play.google.com/store/apps/details?id=com.indovorcorp.egamelan\&hl=in\&gl=US

Sugiyono, S. (2014). Metode Penelitian Penelitian Kuantitatif, Kualitatif dan R\&D. Bandung: Alfabeta.

Sumarsam. (2003). Gamelan: Interaksi Budaya dan Perkembangan Musikal di Jawa. Yogyakarta: Pustaka Pelajar.

Wardhana, Y. W. (n.d.). Digital Audio Workstation (DAW). Retrieved October 23, 2019, from Academia website: https://www.academia.edu/4857282

Wati, E. R. (2016). Ragam Media Pembelajaran (A. Jarot, Ed.). Jakarta: Kata Pena. 